\title{
PAX genes and human neural tube defects: an amino acid substitution in PAX1 in a patient with spina bifida
}

\author{
F A Hol, M P A Geurds, S Chatkupt, Y Y Shugart, R Balling, C T R M \\ Schrander-Stumpel, W G Johnson, B C J Hamel, E C M Mariman
}

Department of Human Genetics, University Hospital Nijmegen, PO Box 9101, $6500 \mathrm{HB}$ Nijmegen, The Netherlands F A Hol

M P A Geurds

B C J Hamel

E C M Mariman

Department of Neurosciences and Pediatrics,

UMDNJ-New Jersey Medical School, Newark, New Jersey, USA

S Chatkupt

Department of Genetics and Development, Colombia University, New York, NY, USA Y Y Shugart

\section{Institut für}

Säugetiergenetik, GSF-Forschungszentru Neuherberg,

Oberschleissheim, Germany

R Balling

Department of Clinical Genetics, University Hospital Maastricht, Maastricht,

The Netherlands

C T R M

Schrander-Stumpel

\section{Department of}

Neurology,

UMDNJ-Robert Wood

Johnson Medical

School, New

Brunswick, New Jersey,

USA

W G Johnson

Correspondence to:

Dr Hol.

Received 27 October 1995 Revised version accepted for publication 22 March 1996

\section{Abstract}

From studies in the mouse and from the clinical and molecular analysis of patients with type 1 Waardenburg syndrome, particular members of the PAX gene family are suspected factors in the aetiology of human neural tube defects (NTD). To investigate the role of PAX1, PAX3, PAX7, and PAX9, allelic association studies were performed in 79 sporadic and 38 familial NTD patients from the Dutch population. Sequence variation was studied by SSC analysis of the paired domain regions of the PAX1, PAX7, and PAX9 genes and of the complete PAX3 gene. In one patient with spina bifida, a mutation in the PAX1 gene was detected changing the conserved amino acid Gln to His at position 42 in the paired domain of the protein. The mutation was inherited through the maternal line from the unaffected grandmother and was not detected in 300 controls. In the PAX3 gene, variation was detected at several sites including a Thr/Lys amino acid substitution in exon 6. All alleles were present among patients and controls in about the same frequencies. However, an increased frequency of the rare allele of a silent polymorphism in exon 2 was found in NTD patients, but no significant association was observed $(p=0.06)$. No sequence variation was observed in the paired domain of the PAX7 and PAX9 genes. Our findings so far do not support a major role of the PAX genes examined in the aetiology of NTD. However, the detection of a mutation in PAX1 suggests that, in principle, this gene can act as a risk factor for human NTD.

(F Med Genet 1996;33:655-660)

Key words: neural tube defects; spina bifida; PAX genes.

Neural tube defects (NTD) constitute a major group of congenital malformations with an incidence of approximately $1 / 1000$ pregnancies. It is generally accepted that they represent multifactorial traits with genetic and environmental factors contributing to the aetiology. Information about the identity of the genetic factors involved is scarce. Induction of NTD by anti-epileptic drugs ${ }^{1}$ and prevention of NTD by folic acid ${ }^{2}$ suggest that genes for drug receptors or metabolic enzymes may play a role. Pedigree analysis and linkage data suggest that the human $\mathrm{X}$ chromosome contains one or more contributing genetic factors. ${ }^{3}$ More specifically, several members of the PAX gene family, encoding a class of related embryonic transcription factors, ${ }^{4}$ have been proposed as candidate genes for NTD. ${ }^{56}$ At present nine members have been identified and studies in the mouse have shown that they are all expressed in the developing brain, the neural tube, or the paraxial mesoderm.

Mutations in the gene for Pax-1 are responsible for the phenotype of the mouse strain undulated with various vertebral anomalies. ${ }^{78}$ Interestingly, litters resulting from a cross between undulated ( $u n)$ and Patch $(P h)$ mice have a high incidence of lumbar spina bifida occulta ${ }^{5}$ indicating that Pax-1 can be involved in specific forms of NTD.

From the association between spina bifida and Waardenburg syndrome type 1 (WS1), ${ }^{9-16}$ the PAX3 gene can be regarded as a risk factor for human NTD. Mutations in this gene have been detected in various patients with both spina bifida and WS1. ${ }^{17-19}$ Moreover, mutations in the murine homologue of this gene cause the Splotch phenotype. Homozygous Splotch mice exhibit severe $\mathrm{NTD}^{6}$ whereas heterozygous Pax-3 mutations seem to increase the incidence of NTD in other predisposed strains. ${ }^{20}$ Linkage analysis has not provided genetic evidence for a major role of PAX3 in human NTD. $^{21}$

The above findings prompted us to investigate further the role of PAX1 and PAX3, and their paralogues PAX9 and PAX7, respectively, by searching for mutations and sequence variants in association with non-syndromic NTD.

\section{Materials and methods}

ASCERTAINMENT OF PATIENTS

Patients with non-syndromic NTD were selected from the Dutch population in collaboration with the Dutch patient organisation BOSK and from the records of our institute. Multiple case families were selected according to the criteria described previously. ${ }^{22}$ In short, there had to be two or more affected members in each family with a close degree of relationship ( $\leqslant 3)$. In this way 38 multiple case families were selected. One affected member of each of these families was included in the present study. The types of NTD in this group were: spina bifida (36), encephalocele (1), and craniorachischisis (1). In addition, a group of 


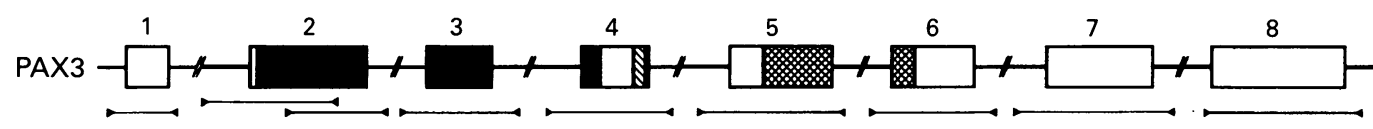

PAX7

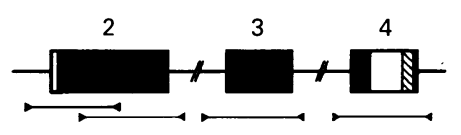

PAX1

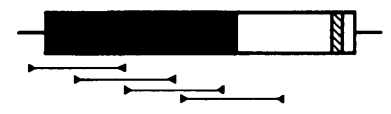

PAX9

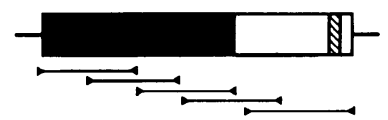

Figure 1 Schematic representation of parts of the different PAX genes that were subjected to SSC analysis. Arrowheads with connecting bars represent the amplification primers and amplified fragments. The filled region, the hatched region, and the double hatched region represent the paired domain, the octapeptide sequence, and the homeodomain, respectively.

79 sporadic patients was also analysed, which included patients with spina bifida (75), with anencephaly (2), and with encephalocele (2). Unaffected and unrelated subjects were randomly chosen from the Dutch population and used as a control group in the present study. Blood was sampled and DNA was extracted according to the procedure of Miller et al. ${ }^{23}$

SSC ANALYSIS

PCR amplification was performed to produce the appropriate DNA fragments (fig 1). Amplification was carried out in a total volume of 25 $\mu \mathrm{l}$ containing $50 \mathrm{ng}$ of genomic DNA, 0.45 $\mathrm{mmol} / \mathrm{l}$ of each primer (table 1; Isogen Bioscience, The Netherlands), $0.1 \mathrm{mmol} / \mathrm{l}$ dCTP, $0.4 \mathrm{mmol} / 1 \mathrm{dATP}, 0.4 \mathrm{mmol} / 1 \mathrm{dGTP}$, $0.4 \mathrm{mmol} / 1$ dTTP, $0.1 \mu \mathrm{l} \quad[\alpha[32] \mathrm{P}] \mathrm{dCTP}$ (Amersham) in PCR buffer $(50 \mathrm{mmol} / \mathrm{l} \mathrm{KCl}$, $10 \mathrm{mmol} / 1$ TRIS-HCl, $\mathrm{pH} 8.3,1 \mathrm{mmol} / 1 \mathrm{DTE}$, $0.001 \%$ gelatine, $1.5-6 \mathrm{mmol} / 1 \mathrm{MgCl}_{2}$ ) with $0.5 \mathrm{U}$ of Taq DNA polymerase (Boehringer, Mannheim). Samples were denatured at $92^{\circ} \mathrm{C}$ for five minutes and then subjected to 35 cycles of amplification: $92^{\circ} \mathrm{C}$ for 50 seconds, $55^{\circ} \mathrm{C}$ for 50 seconds, $72^{\circ} \mathrm{C}$ for one minute 30 seconds. Aliquots of the amplified DNA were mixed with 1 volume formamide dye buffer, denatured at $95^{\circ} \mathrm{C}$ for five minutes, and placed on ice. Samples $(4 \mu \mathrm{l})$ were loaded on a $5 \%$ non-denaturing polyacrylamide gel containing $10 \%$ glycerol and on a similar gel without glycerol. Electrophoresis was for 3-6 hours at $40 \mathrm{~W}$ and $4^{\circ} \mathrm{C}$. The gels were dried and exposed overnight on Kodak X-omat S film.

SEQUENCING OF NORMAL AND VARIANT ALLELES To determine the molecular nature of the shifted bands observed by SSC analysis, bands representing wild type and variant alleles were cut out of the gel. DNA was eluted from each of the gel slices in $50 \mu$ l aquadest for one hour at $37^{\circ} \mathrm{C}$ and reamplified under the conditions described above. Subsequently, the amplified DNA fragments were purified by electrophoresis on a $1 \%$ agarose gel (one hour, $10 \mathrm{~V} / \mathrm{cm}$ ),

Table 1 Primers used for SSC analysis ${ }^{1828-31}$

\begin{tabular}{llll}
\hline & Size $(b p)$ & Forward primer & Reverse primer \\
\hline PAX3 & & & \\
1 & 138 & 5'-CCTGGATATAATTCCGAGCG-3' & 5'-CGCTGAGGCCCTCCCTTA-3' \\
2A & 266 & 5'-GAAGACTGCGAAATTACGTGCTGC-3' & 5'-ACAGGATCTTGGAGACGCAGCC-3' \\
2B & 208 & 5'-AACCACATCCGCCACAAGATCG-3' & 5'-GACCACAGTCTGGGAGCCAGGAGG-3' \\
3 & 237 & 5'-CACCTGGCCCAGGGTACCGGGTAC-3' & 5'-CGGGGTAATAGCGACTGACTGTC-3' \\
4 & 252 & 5'-AGCCCTGCTTGTCTCAACCATGTG-3' & 5'-TGCCCTCCAAGTCACCCAGCAAGT-3' \\
5 & 304 & 5'-GACTTGGATCAATCTCAGTTTT-3' & 5'-TAGGACACGGAGGTTTGG-3' \\
6 & 250 & 5'-TTCATCAGTGAAATCCTTAAATT-3' & 5'-CGCCTGGAAGTTACTTTCTA-3' \\
7 & 320 & 5'-GAACTTTCTCTGCTGGCCTA-3' & 5'-TGGTTCTGGTATACAGCAAATC-3' \\
8 & 313 & 5'-GCTCTTTTTTTAGGTAATGGGA-3' & 5'-TGAGTTTATCTCCCTTCCAGG-3' \\
PAX7 & & & \\
$2 A$ & 188 & 5'-TCCATCCTCACCCTGCACCT-3' & 5'-CGGGAGATGACACAGGGCCG-3' \\
$2 B$ & 214 & 5'-GCGACCCCTGCCTAACCACA-3' & 5'-AAGCCAGCTGCCAGCCTCTGTG-3' \\
3 & 200 & 5'-CCCCATCCCATCTTTCCACTC-3' & 5'-TGCCGGCTCAGCTGCCTTCTCA-3' \\
4 & 189 & 5'-TTGCTCTTTTGCCTTTGAATTTCT-3' & 5'-GCCTCGCAGCCCAGGGAA-3' \\
PAX1 & & & \\
1 & 194 & 5'-TCCGGCTCACTCTTGTCTGG-3' & 5'-ATCTTGCTCACGCAGCCGTG-3' \\
2 & 201 & 5'-ACGCCATCCGCTTGCGCATT-3' & 5'-AGTCCCGGATGTGCTTGACC-3' \\
3 & 200 & 5'-CCTGGCGCGCTACAACGAGA-3' & 5'-TGGAGCTCACCGAAGGCACA-3' \\
4 & 200 & 5'-CTGGCATCTTTGCCTGGGAG-3' & 5'-AGGGGTACTGGTAGATGTGG-3' \\
PAX9 & & & \\
1 & 200 & 5'-ATTTTGCAGAGCCAGCCTTC-3' & 5'-CGAGCCCGTCTCGTTGTATC-3' \\
2 & 188 & 5'-GGCCCAACTGGGCATCCGAC-3' & 5'-GGTCTCTCTGCTTGTAGGTC-3' \\
3 & 202 & 5'-ATCTTGCCAGGAGCCATCGG-3' & 5'-TGCCGATCTTGTTGCGCAGAAT-3' \\
4 & 200 & 5'-ATCTTCGCCTGGGAGATCCGG-3' & 5'-GGGTACGAGTAGATGTGGTGT-3' \\
5 & 222 & 5'-ATTACGACTCATACAAGCAGCACC-3' & 5'-CCCTACCTTGGTCGGTGATGG-3' \\
& & &
\end{tabular}


allowed to migrate into ultra low gelling temperature agarose (Sigma), and sliced out of the gel. This material served as substrate for direct sequencing using a cycle sequence kit according to the protocol of the manufacturer (BRL). Sequences were determined in two directions with the forward and reverse amplification primers after 5 ' end labelling with [32]P. Whenever the resolution was too poor to cut the allelic bands out of the SSC gel separately, non-radioactive PCR was performed on genomic DNA. Amplification products were purified on an agarose gel and cloned into the SmaI site of plasmid vector Bluescript $\mathrm{SK}^{+}$(Stratagene). Dideoxy DNA sequencing was conducted on double stranded DNA from positive clones using the $\mathrm{T} 7$ sequencing kit (Pharmacia) with T7 and T3 primers. Sequences were obtained from at least three independent clones.

\section{Results}

SSC ANALYSIS OF THE PAX1 AND PAX9 GENES Double mutant mice with the genotype \{un/ un; $\mathrm{Ph} /+\}$ exhibit an occult form of spina bifida ${ }^{5}$ indicating that mutations in Pax-1 can influence the development of the vertebral arches. In order to assess the relevance of PAX1 for human NTD, the paired domain region, which is the only part of the gene that has been cloned to date, was subjected to SSC analysis. DNA from 79 sporadic and 38 familial NTD patients from the Dutch population was screened for the presence of sequence variation (fig 1). This resulted in the detection of a shifted band in a single sporadic patient with spina bifida (fig 2A). Direct sequencing of the shifted fragment showed a nucleotide substitution ( $\mathrm{G} \rightarrow \mathrm{C}$, fig $3 \mathrm{~A}$ ) leading to the exchange of glutamine at position 42 of the paired domain by histidine. This nucleotide substitution disrupts an $A l u \mathrm{I}$ restriction site in the gene. Therefore, the presence of the base change could be confirmed by AluI restriction digestion of the PCR product leaving the DNA from this patient intact (fig 4). In the same way it was shown that the base change was absent from 300 unaffected controls suggesting that this alteration is aetiologically related to the NTD of this person. Moreover, the functional importance of the Gln residue at this position is corroborated by the fact that it has been conserved between several human PAX genes as well as the murine Pax-1 gene (fig 5). Finally, the predicted structure of the mutant peptide showed the loss of a beta sheet conformation surrounding the displaced amino acid (fig 6). Together, these results argue for a contribution of the PAX1 mutation to the development of spina bifida in one patient. However, the same mutation was also found in the unaffected mother and grandmother showing that this factor alone is not sufficient to induce a NTD during embryogenesis.

In addition, we have examined all patients for sequence variation in the paired domain of the PAX9 gene (fig 1), which is highly homologous to the PAX1 gene. No band shifts were detected.

SSC ANALYSIS OF THE PAX3 AND PAX 7 GENES Although linkage studies have not provided any indication for PAX3 being a major aetiological factor for familial NTD, ${ }^{21}$ a less prominent role cannot be excluded in this way, in particular for sporadic cases. Therefore, a similar strategy was applied as performed for the PAX1 gene, that is, using SSC analysis to search for mutations or rare sequence variants primarily occurring among patients. The complete coding sequence of the PAX3 gene contained in exons 1 to 8 , together with their flanking intron sequences, were analysed (fig 1). The most dramatic change in the banding patterns was observed for exon 5 in a familial patient. The detailed analysis of this case, which turned out to be a 5 bp deletion causing spina bifida and WS 1 , has been described elsewhere. ${ }^{19}$ Besides the normal band pattern, shifted bands were detected for exons 2,6 , and 7 (fig 2). The nature of the observed shifts was determined as described in Materials and methods. One of the shifts observed for the exon 2 fragment (fig 2B) and the shift observed for the exon 7 frag-
P C C

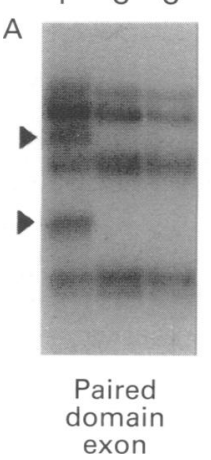

P C C

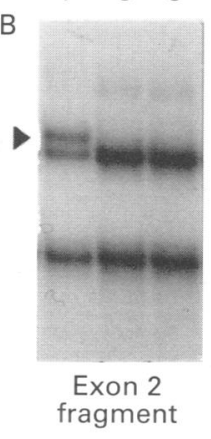

C C

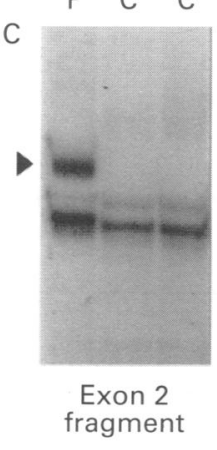

P C C

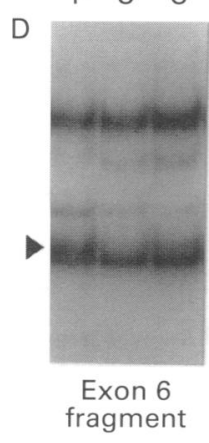

P C C

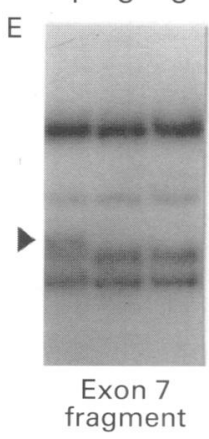

Figure 2 Allelic band pattern obtained through SSC analysis of different fragments of the PAX1 gene $(A)$ and the PAX3 gene $(B-E)$. The first lane shows the altered pattern $(P)$ which was occasionally observed in patients or controls or both, whereas the more common SSC pattern (C) is shown in lanes 2 and 3. Arrowheads mark the observed shifted allelic bands. 
Table 2 Frequencies of the different SSC shifts in the PAX3 gene in Dutch patients and controls

\begin{tabular}{lllllll}
\hline & \multicolumn{3}{l}{ Patients } & & & \multicolumn{2}{l}{ Controls } \\
\cline { 2 - 3 } \cline { 6 - 7 } SSC fragment & No & Frequency & & No & Frequency \\
\hline Exon 2 (5' intron polymorphism) & $5 / 64$ & 0.08 & & $8 / 93$ & 0.09 \\
Exon 2 (silent polymorphism) & $42 / 113$ & 0.37 & & $60 / 229$ & 0.26 \\
Exon 6 (AA polymorphism) & $3 / 61$ & 0.05 & & $6 / 93$ & 0.06 \\
Exon 7 (3' intron polymorphism) & ND & - & & ND & - \\
\hline
\end{tabular}

ment (fig 2E) were shown to represent single nucleotide substitutions in the $5^{\prime}$ and $3^{\prime}$ flanking intronic sequences of exon $2(T \rightarrow C$, fig $3 \mathrm{~B})$ and $7(\mathrm{G} \rightarrow \mathrm{A}$, fig $3 \mathrm{E})$, respectively. Another shift of the same fragment of exon 2 (fig 2C) turned out to be the result of a single nucleotide substitution $(\mathrm{C} \rightarrow \mathrm{T})$ at the third position of codon 43 representing a silent base change (Gly43Gly, fig 3C), which has previously been reported by Tassabehji et al. ${ }^{24}$ In the $3^{\prime}$ half of exon 6, a $C \rightarrow A$ change was identified (fig 2D) downstream of the homeodomain

A

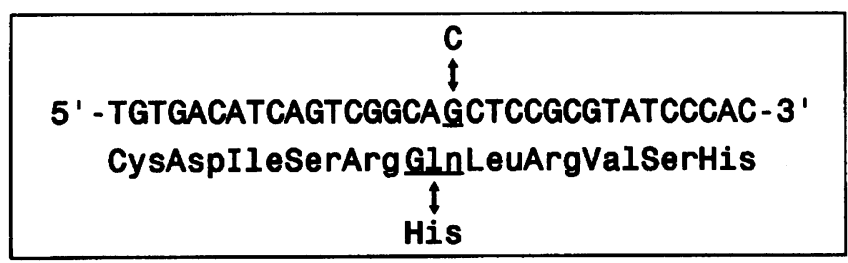

B

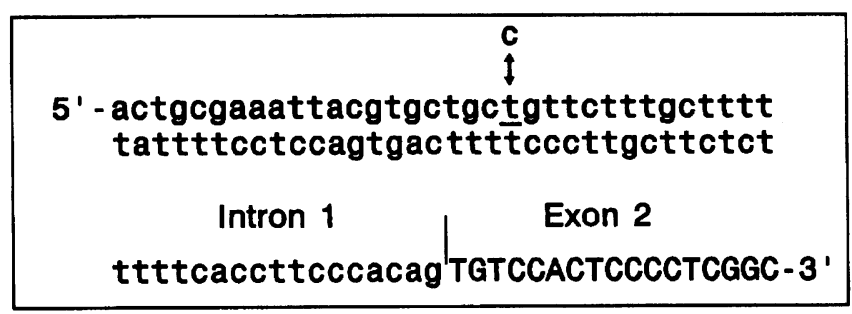

C

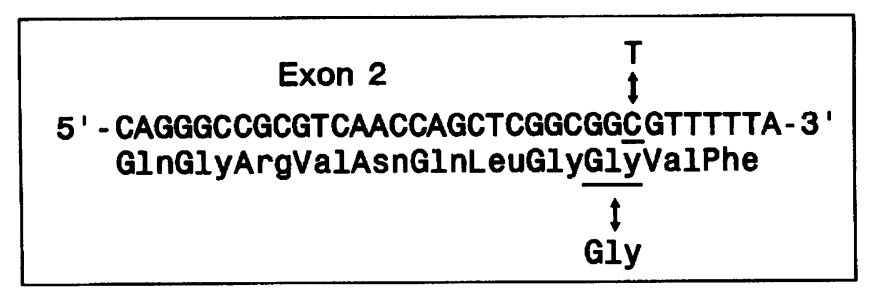

D

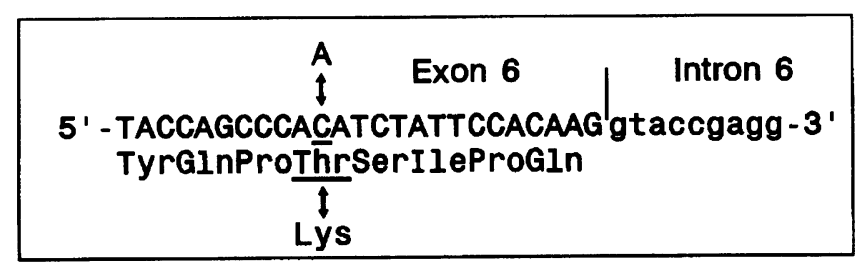

E

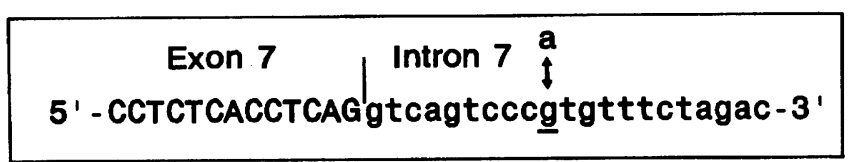

Figure 3 Partial DNA and protein sequence of the paired domain exon of PAX1 $(A)$, as well as PAX3 exon $2(B, C)$, exon $6(D)$, and exon $7(E)$. The nucleotide substitutions that are responsible for the SSC shifts in fig 2 are shown. When the nucleotide substitution gives rise to an amino acid substitution in the deduced peptide, this is also shown.
Table 3 Frequency of the $T$ allele chromosome of the exon $2 \mathrm{C} / \mathrm{T}$ polymorphism in Dutch patients and controls

\begin{tabular}{|c|c|c|c|c|c|}
\hline & \multicolumn{2}{|l|}{ Patients } & \multicolumn{2}{|l|}{ Controls } & \multirow[b]{2}{*}{ p value } \\
\hline & No & Frequency & No & Frequency & \\
\hline $\mathrm{T}$ allele & $46 / 226$ & 0.20 & $67 / 458$ & 0.15 & 0.06 \\
\hline
\end{tabular}

resulting in an amino acid substitution (Thr315Lys, fig 3D). According to the structure prediction analysis (not shown) this amino acid substitution does not seem to be influencing the protein structure. Genotyping of the control group showed that all the sequence variants were present both in patients and controls with approximately equal frequencies in both groups (table 2). Interestingly, the $\mathrm{T}$ allele of the exon 2 silent polymorphism seemed to be present more often in patients than in controls. However, a thorough analysis of the data (heterozygosity/homozygosity scoring, $\mathrm{T}$ allele frequency determination) applying chi-square statistics, did not show a significant association between the $\mathrm{T}$ allele and NTD $(\mathrm{p}=0.06$, odds $T$ ratio $=1.49,95 \%$ confidence interval 0.96 P 2.30; table 3).

A Finally, for PAX7, which closely resembles $\mathrm{X}$ PAX3 in structure and expression, the same 1 groups of patients and controls were screened 1 for the presence of sequence variation in the $\perp$ paired domain (exons 2 to 4 , fig 1 ), which is the only part of this gene cloned so far. No band shifts were detected in the SSC analysis.

\section{Discussion}

PAX genes encode a class of highly conserved transcription factors with a characteristic DNA binding paired domain, which play important roles in embryonic development. ${ }^{4}$ To determine more accurately the extent to which genetic variation in the PAX 1 and PAX3 genes, and their paralogues PAX9 and PAX7, might predispose to NTD we have performed SSC analysis of both familial and sporadic patients. Analysis of the paired domain of PAX1 showed a missense mutation in one sporadic NTD patient. The NTD was detected by amniocentesis and biochemical analysis of amniotic fluid, indicated by the fact that the mother was a known carrier of a balanced translocation A $t(7 ; 20)(q 22 ; q 13.2)$. After pregnancy termina3 tion at 19 weeks of gestation, clinical examination showed an open lumbar spina bifida of about $1.5 \mathrm{~cm}$ in size. Uniparental disomy of chromosome 7 or 20 in the fetus was excluded by the analysis of genetic markers. Cytogenetic analysis showed the presence of the same balanced translocation in the fetus and the maternal grandmother. Apparently, the mutation in the PAX1 gene, which is located at $20 \mathrm{p} 11$, cosegregates with the translocation chromosomes. Although there is no indication for a major pathological effect of the balanced translocation, an influence on the phenotype of the fetus cannot be excluded. In fact, under a multifactorial threshold model both genetic abnormalities, that is, the PAX1 mutation and the translocation, may have contributed to the appearance of the NTD. 

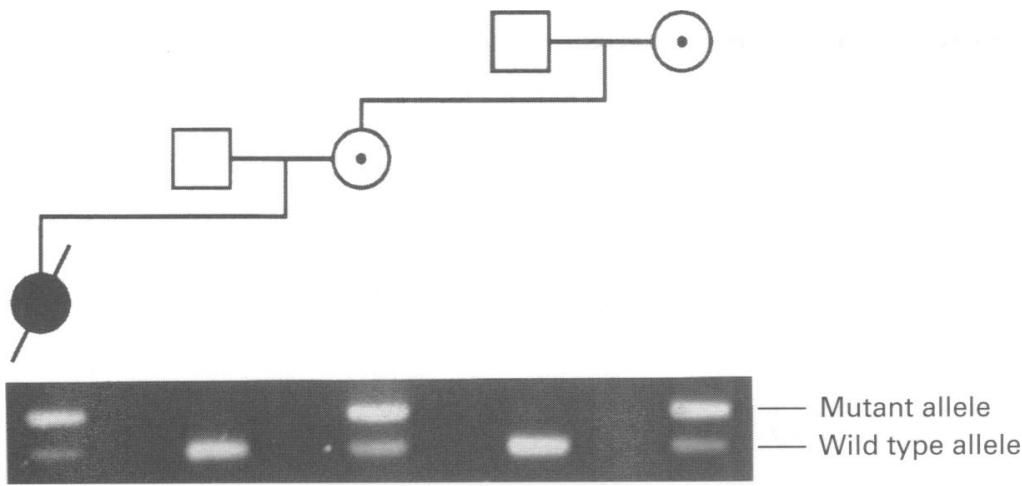

Figure 4 Pedigree of the family in which the PAX1 mutation is segregating. Presence of the mutation could be confirmed by AluI restriction digestion of the amplified PAX1 paired domain fragment. Heterozygous carriers show a mutant allelic band in addition to the wild type band.

\section{PAX1 HUMAN \\ PaX1 MOUSE \\ PAX3 HUMAN \\ PAX7 HUMAN \\ PAX9 HULAN \\ PAX1 PATIENT}

Figure 5 Partial protein sequence of different human and murine PAX genes showing that the glutamine $(O)$ residue at this position in the paired domain of the PAX1 gene is highly conserved. The patient carrying the PAX1 mutation has a histidine $(H)$ residue at this position.

Based on data from the Splotch mouse and from the analysis of families and patients with Waardenburg syndrome, the PAX3 gene is a likely candidate for neural tube defects. Linkage analysis of multiple case families with the dinucleotide repeat marker ${ }^{25}$ immediately upstream of the PAX 3 gene did not provide any indication for a major involvement of this gene. ${ }^{21}$ However, situations of negative linkage but positive allelic association have been reported for other genes and disorders, such as the TGF $\alpha$ gene in cleft lip and cleft palate. ${ }^{26}{ }^{27}$ With respect to NTD, no significant associ-

A

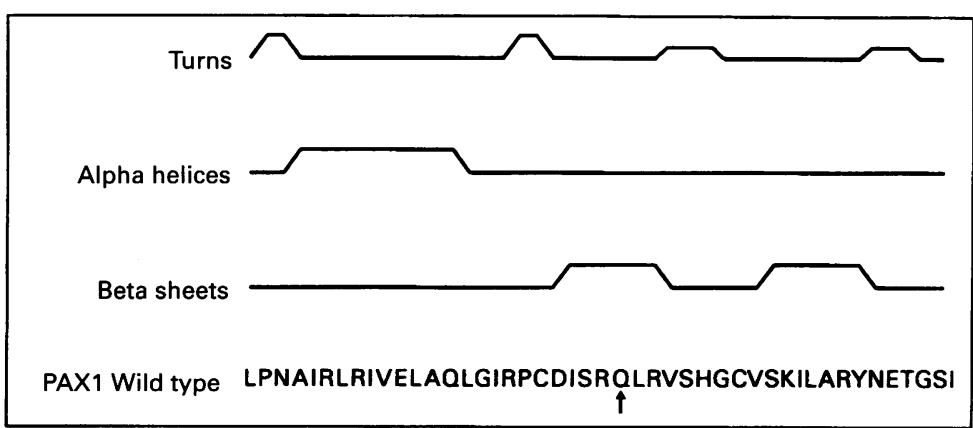

B

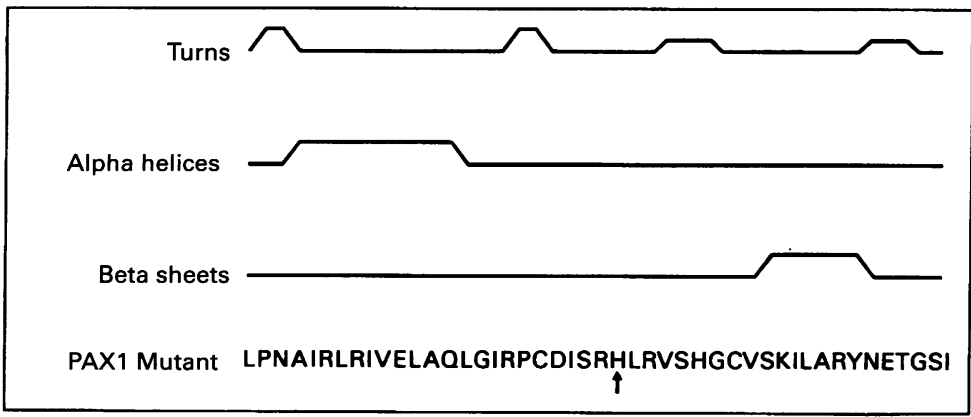

Figure 6 Results of the secondary protein structure prediction, of the wild type $(A)$ and mutant (B) PAX1 peptide, respectively. Computer analysis, using the Chou-Fasman algorithm, shows the loss of a $\beta$ sheet conformation at the position of the mutation. ation ( $p>0.1)$ was observed with any of the alleles of the dinucleotide polymorphism and similar results were obtained using patients and controls from the US population (not shown). Moreover, no significant association was observed between NTD and the newly detected polymorphisms described in this study, although suggestive results were obtained with the $\mathrm{T}$ allele of a $\mathrm{C} / \mathrm{T}$ silent polymorphism in exon $2(p=0.06)$. The $T$ at the polymorphic site by itself does not necessarily have to be pathogenic to explain a possible association; however, one could imagine that a difference in codon usage or pre-mRNA processing might lead to a slight inequality in expression efficiency between both allelic forms of the PAX3 gene. In this respect, embryos with a $T$ allele would have a minor disadvantage during neurulation. However, at this point the evidence for association is not convincing and additional groups of patients need to be studied to determine whether the increased frequency of the $\mathrm{T}$ allele in our patients has relevance for nonsyndromal NTD.

In this study we have investigated whether particular members of the PAX gene family could play a role in the aetiology of human NTD. No indications for an involvement of PAX7 and PAX9 have been obtained so far. No significant association was detected between PAX3 and non-syndromal NTD. On the other hand, when considering the increased frequency of NTD in WS 1 families, ${ }^{19}$ PAX3 mutations do seem to predispose to certain syndromic forms of NTD. Our present results argue for a role of the PAX1 gene in the aetiology of NTD as shown by the detection of a missense mutation in the paired domain. At the same time our data show that the detected mutation in PAX1 is not sufficient to cause the development of the disorder. Other factors, environmental or genetic or both, would have to exert a negative influence on the neurulation process to increase the risk further. From animal studies ${ }^{5}$ the gene for PDGFR $\alpha$ underlying the Patch phenotype is a suspected candidate.

We thank the Dutch Working Group on Hydrocephalus and Spina Bifida of the patient organisation BOSK for their help in contacting the patients and families. We also thank Prof Dr $\mathrm{H} \mathrm{H}$ Ropers and Professor T Strachan for helpful discussions and S van der Velde-Visser and E van Rossum-Boenders for cell culture and EBV transformations. This study was supported by the Dutch Prinses Beatrix Fonds grant No 93-005 and 95-0521. The cooperation of the families and the 93-0 5 and 95-0521. The cooperation of the families and the staff of spina bifida clinics in the USA is gratefully acknowledged. The support of NIH grants R29 NS29893 (SC) and HG00008 (YS) and the March of Dimes Birth Defects Foundation (WJ, SC) is gratefully acknowledged. We also thank $\mathrm{Q} \mathrm{Li}, \mathrm{C}$ Torigian, A Sarangi, and E S Stenroos for technical assistance. FH, RB, BH and EM are members of INTEGER, the International Neura Tube Embryology, Genetics and Epidemiology Research consortium to identify genes which predispose to neural tube defects.

1 Jager-Roman E, Deichl A, Jakob S, et al. Fetal growth, major malformations, and minor anomalies in infants born to women receiving valproic acid. $\mathcal{f}$ Pediatr 1986;108:9971004

2 MRC Vitamin Study Research Group. Prevention of neural tube defects: results of the Medical Research Council Vitamin Study. Lancet 1991;338:131-7.

3 Hol FA, Geurds MPA, Jensson O, et al. Exclusion mapping of the gene for $\mathrm{X}$-linked neural tube defects in an Icelandic family. Hum Genet 1994;93:452-6.

4 Strachan T, Read AP. PAX genes. Curr Opin Genet Dev 1994;4:427-38. 
5 Helwig U, Imai K, Schmahl W, et al. Interaction between undulated and Patch leads to an extreme form of spina bifida in double-mutant mice. Nature Genet 1995;11:60-3.

6 Moase CE, Trasler DG. Splotch locus mouse mutants: models for neural tube defects and Waardenburg syndrome els for neural tube defects and Waardenburg

7 Balling R, Deutsch U, Gruss P. undulated, a mutation affecting the development of the mouse skeleton, has a poin mutation in the paired box of Pax-1. Cell 1988;55:531-5.

8 Wallin J, Wilting J, Koseki H, Fritsch R, Christ B, Balling R The role of Pax-1 in axial skeleton development. Development 1994;120:1109-21.

9 De Saxe M, Kromberg JGR, Jenkins T. Waardenburg syndrome in South Africa. Part I. An evaluation of the clinical findings in 11 families. $S$ Afr Med $\mathcal{f} 1984 ; 66: 256$ 61.

10 Narod SA, Siegel-Bartelt J, Hoffman HJ. Cerebellar infarction in a patient with Waardenburg syndrome. $A m \mathcal{f} \mathrm{Med}$ tion in a patient with

11 Da-Silva EO. Waardenburg I syndrome: a clinical and genetic study of two large Brazilian kindreds, and literature genetic study of two large Brazilian kind
review. $A m \tilde{f}$ Med Genet $1991 ; 40: 65-74$

12 Carezani-Gavin M, Clarren SK, Steege T. Waardenburg syndrome associated with meningomyelocele. $\mathrm{Am} \mathcal{F} \mathrm{Me}$ Genet 1992;42:135-6.

13 Begleiter ML, Harris DJ. Waardenburg syndrome and meningocele. Am F Med Genet 1992;44:541.

14 Chatkupt S, Chatkupt S, Johnson WG. Waardenburg syndrome and myelomeningocele in a family. 7 Med Genet 1993;30:83-4.

15 Moline ML, Sandlin C. Waardenburg syndrome and meningomyelocele. Am $\mathcal{F}$ Med Genet 1993;47:126.

16 Aymé S, Philip N. Possible homozygous Waardenburg syndrome in a fetus with exencephaly. Am f Med Genet 1995; 59:263-5.

17 Baldwin CT, Hoth CF, Amos JA, da-Silva EO, Milunsky A An exonic mutation in the HuP2 paired domain gene
causes Waardenburg's syndrome. Nature 1992;355:637-8.

18 Hoth CF, Milunski A, Lipsky N, Sheffer R, Clarren SK Baldwin CT. Mutations in the paired domain of the human PAX3 gene cause Klein-Waardenburg syndrom (WS-III) as well as Waardenburg syndrome type I (WS-I) Am ₹ Hum Genet 1993;52:455-62.

$19 \mathrm{Hol}$ FA, Hamel BCJ, Geurds MPA, et al. A frame shift mutation in the gene for PAX 3 in a girl with spina bifida and mild symptoms of Waardenburg syndrome. 7 Med Genet 1995;32:52-6.
20 Estibeiro JP, Brook FA, Copp AJ. Interaction between splotch (Sp) and curly tail (ct) mouse mutants in the splotch (Sp) and curly tail (ct) mouse mutants in the
embryonic development of neural tube defects. Development 1993;119:113-21.

21 Chatkupt S, Hol FA, Shugart YY, et al. Absence of linkage between familial neural tube defects and PAX3 gene. $f$ Med Genet 1995;32:200-4.

22 Mariman ECM, Hamel BCJ. Sex ratios of affected and transmitting members of multiple case families with neural tube defects. $\mathcal{F}$ Med Genet 1992;29:695-8.

23 Miller SA, Dykes DD, Polesky HF. A simple salting out procedure for extracting DNA from human nucleated cells. Nucleic Acids Res 1988;16:1215.

24 Tassabehji M, Newton VE, Leverton K, et al. PAX3 gene structure and mutations: close analogies between Waardenburg syndrome and the Splotch mouse. Hum Molec Genet 1994;3:1069-74.

25 Wilcox ER, Rivolta MN, Ploplis B, Potterf SB, Fex J. The PAX 3 gene is mapped to human chromosome 2 together with a highly informative CA dinucleotide repeat. Hum Molec Genet 1992;1:215.

26 Ardinger HH, Buetow KH, Bell GI, Bardach J, VanDemark R, Murray JC. Association of genetic variation of the transforming growth factor alpha gene with cleft lip and palate. Am f Hum Genet 1989;45:348-53.

27 Chenevix-Trench G, Jones K, Green AC, Duffy DL, Martin NG. Cleft lip with or without cleft palate: associations with transforming growth factor alpha and retinoic acid recep transforming growth factor alpha and retino

28 Burri M, Tromvoukis Y, Bopp D, Frigerio G, Noll M. Conservation of the paired domain in metazoans and its structure in three isolated human genes. $E M B O \mathcal{F} 1989 ; 8: 1183$ 90.

29 Tassabehji M, Read AP, Newton VE, et al. Waardenburg's syndrome patients have mutations in the human homologue of the Pax-3 paired box gene. Nature 1992; 355:635-6.

30 Macina R, Barr F, Galili N, Reithman H. Genomic organization of the human PAX 3 gene: DNA sequence analysis of the region disrupted in alveolar rhabdomyosarcoma. Genomics 1995;26:1-8.

31 Stapleton P, Weith A, Urbanek P, Kozmik Z, Busslinger M. Chromosomal localization of seven PAX genes and cloning of a novel family member, PAX9. Nature Genet 1993;3:292-7. 